\title{
Molecular detection and genomic characterization of porcine circovirus 3 in pigs from Northeast China
}

\author{
Zhuo Ha ${ }^{1} \mathbb{D}$, Chang-zhan Xie ${ }^{2,3}$, Jin-feng Li $i^{5}$, Shu-bo Wen ${ }^{2}$, Ke-long Zhang ${ }^{6}$, Fu-long Nan ${ }^{5}$, He Zhang ${ }^{2}$, \\ Ying-cheng Guo ${ }^{4}$, Wei Wang ${ }^{2,7}$, Hui-jun Lu $\mathrm{Lu}^{2,7^{*}}$ and Ning-yi Jin ${ }^{1,2,7^{*}}$
}

\begin{abstract}
Background: First identified in the United States in 2016, porcine circovirus type 3 (PCV3) is a newly emerging porcine circovirus exhibiting a wide range of clinical syndromes, which may be associated with the pathogenicity observed in pigs.

Results: The aim of this study was to identify and characterize the full genome sequence of PCV3 strains circulating in Northeast China. Herein, 105 lung samples isolated from sick pigs in Northeast China during 2018 were analyzed for PCV3. Using PCR, the total PCV3-positive rate was 33.3\% (35/105), with rates of 17.8\% (8/45), 66.7\% (10/15), and $37.8 \%(17 / 45)$ in Heilongjiang, Jilin, and Liaoning province, respectively. Additionally, our findings showed that PCV3-positive samples had a high rate of co-infection with PCV2, PPV6, and PPV7. To study the evolution of the PCV3 in Northeast China, we sequenced the entire genome of 13 strains of PCV3. The results of phylogenetic analyses revealed that PCV3 could be divided into two clades, PCV3a and PCV3b. Interestingly, a G deletion at position 1072 was found in the 1999 nt genome of PCV3-CN2018LN-4 (MH277118). The G deletion terminated replicase protein translation and induced a truncated replicase protein.
\end{abstract}

Conclusion: These results contribute to the understanding of PCV3 molecular epidemiology and evolution in Northeast China. A new strain of PCV3 with truncated replicase protein was identified.

Keywords: PCV3, Northeast China, Co-infection, Complete genome, Replicase protein

\section{Background}

Porcine circovirus is a small non-enveloped virus with a circular, single-stranded DNA genome, belonging to the family Circoviridae [1]. Porcine circovirus 1 (PCV1) was initially identified in the 1970 s as a contaminating agent in pig kidney cells and was considered nonpathogenic for swine [2, 3]. Porcine circovirus type 2 (PCV2), known as an essential pathogen of porcine circovirus-associated disease (PCVAD) clinically manifests as postweaning multisystemic wasting syndrome (PMWS), porcine dermatitis and nephropathy syndrome (PDNS), and reproductive failure, resulting in huge economic losses for the swine

\footnotetext{
*Correspondence: huijun_lu@126.com; ningyik@126.com

${ }^{2}$ Institute of Military Veterinary medicine, Academy of Military Medical Sciences, Changchun 130122, China

${ }^{1}$ College of Veterinary Medicine, Northeast Agricultural University, Harbin 150030, China

Full list of author information is available at the end of the article
}

industry [4-6]. Currently, a novel circovirus termed porcine circovirus 3 (PCV3), was identified in the United States by metagenomic sequencing. PCV3 is characterized by PDNS, reproductive failure, as well as cardiac and multisystemic inflammation $[7,8]$. Subsequently, other researchers found that PCV3 might be associated with congenital tremors $(\mathrm{CT})$ and porcine respiratory disease complex (PRDC) $[9,10]$. In addition, several strains of circovirus were found to be associated with different clinical diseases, such as fox circovirus, dog circovirus and duck circovirus [11-13]. Therefore, these data indicate that PCV3 might be associated with pathogenicity in pigs.

Similar to PCV2, PCV3 has a circular single-stranded DNA genome ranging in size from 1999 to 2001 nucleotides, containing two major open reading frames (ORFs), ORF1 and ORF2, which code for a 296 amino acid (aa) replicase protein (rep) and 214 aa capsid protein (cap),

(c) The Author(s). 2018 Open Access This article is distributed under the terms of the Creative Commons Attribution 4.0 International License (http://creativecommons.org/licenses/by/4.0/), which permits unrestricted use, distribution, and reproduction in any medium, provided you give appropriate credit to the original author(s) and the source, provide a link to the Creative Commons license, and indicate if changes were made. The Creative Commons Public Domain Dedication waiver (http://creativecommons.org/publicdomain/zero/1.0/) applies to the data made available in this article, unless otherwise stated. 
respectively $[7,8]$. PCV3 is widely circulated across the world, including the United States, China, Italy, Brazil, Korea, German, Denmark, and Spain [14-19]. In addition, increasing evidence has shown that PCV3 co-infections with other pathogens might be associated with increased pathogenicity in pigs $[8,20]$. Moreover, the study by Li et al. demonstrated that PCV3 could be divided into two clades using the complete coding sequences [21, 22]. However, a greater number of $\mathrm{PCV} 3$ sequences are required to verify the division of PCV3 into different clades. In the present study, we investigated the extent of infection and co-infection of PCV3 in Northeast China. Furthermore, 62 complete coding sequences (13 in this study) were used for phylogenetic analysis and dividing PCV3 into different clades. More importantly, a new strain of PCV3 with a 13 aa deletion in the replicase protein was identified.

\section{Results}

Characteristics of the PCV3 epidemic in Northeast China Of the 105 clinical lung samples obtained from sick pigs in Northeast China, the total PCV3-positive rate was 33.3\% (35/105), with $17.8 \%$ (8/45) positivity in Heilongjiang, $66.7 \%$
(10/15) in Jilin, and 37.8\% (17/45) in Liaoning. In addition, both the present and previous studies demonstrate that the presence of PCV3 is extensive in China (Fig. 1).

\section{PCV3 co-infection with other pathogens}

Among the 35 PCV3-positive samples, co-infection of PCV3 with other pathogens, including CSFV, PRRSV, SIV, PRV, PPV2, PPV6, PPV7, TTSuV1, TTSuV2, and PCV2 was analyzed. As shown in Table 1, PCV3 co-infections with PRRSV, PCV2, TTSuV1, TTSuV2, PPV2, PPV6, and PPV7 were detected in $11.4 \%(4 / 35), 45.7 \%(16 / 35), 34.3 \%(12 / 35)$, $25.7 \%$ (9/35), $25.7 \%$ (9/35), 60.0\% (21/35), and 74.3\% (26/35) of the samples, respectively. In contrast, neither CSFV, SIV, nor PRV were detected in the PCV3-positive samples. These data indicate that a high co-infection rate of $\mathrm{PCV} 3$ with PCV2, PPV6, and PPV7 exists, which provide valuable information for further study into the pathology of PCV3 in association with PCV2, PPV6, and PPV7.

\section{Sequence comparison and phylogenetic analysis of PCV3}

To analyze the genetic relationship of PCV3 strains collected in Northeast China, 13 complete sequences of

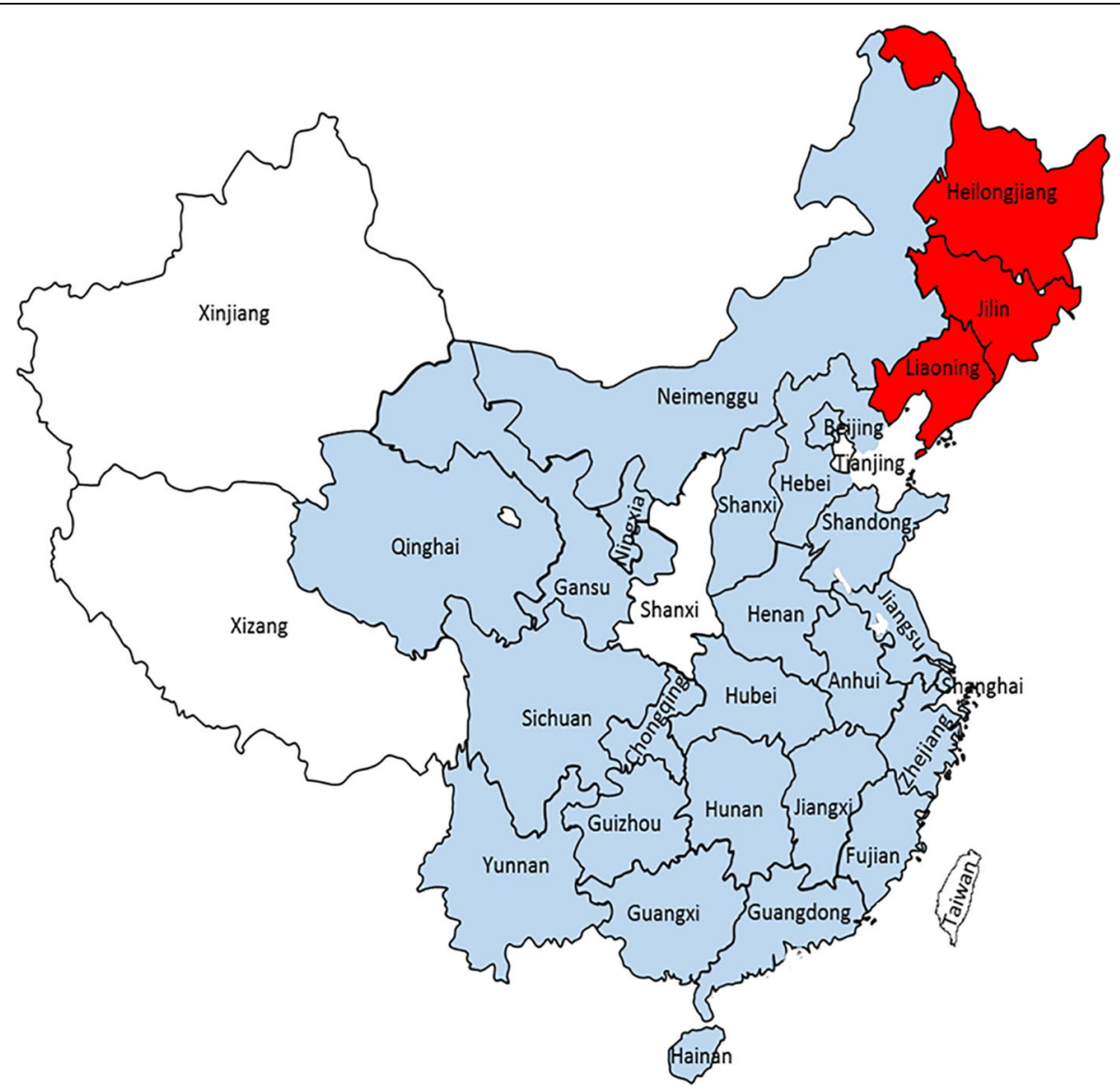

Fig. 1 Geographical distributions of PCV3 in China. Red represents the PCV3-positive provinces in this study. Light blue represents the PCV3positive provinces in previous reports $[14,20,26,27]$ 
Table 1 Detection of PCV3 co-infections with PRRSV, PCV2, TTSUV1, TTSUV2, PPV2, PPV6, PPV7, CSFV, PRV, and SIV in tissue samples isolated from sick pigs during 2018

\begin{tabular}{|c|c|c|c|c|c|c|c|c|c|c|c|c|}
\hline \multirow[t]{2}{*}{ Geographical origin } & \multirow{2}{*}{$\begin{array}{l}\text { Number of } \\
\text { samples }\end{array}$} & \multirow{2}{*}{$\begin{array}{l}\text { PCV3 } \\
\text { positive }\end{array}$} & \multicolumn{10}{|c|}{ Co-infection } \\
\hline & & & PRRSV & PCV2 & TTSuV1 & TTSuV2 & PPV2 & PPV6 & PPV7 & CSFV & PRV & SIV \\
\hline Heilongjiang & 45 & $8 / 45$ & $3 / 8$ & $3 / 8$ & $4 / 8$ & $2 / 8$ & $2 / 8$ & $6 / 8$ & $6 / 8$ & $0 / 8$ & $0 / 8$ & $0 / 8$ \\
\hline Jilin & 15 & $10 / 15$ & $0 / 10$ & $6 / 10$ & $1 / 10$ & $2 / 10$ & $3 / 10$ & $5 / 10$ & $5 / 10$ & $0 / 10$ & 0/10 & $0 / 10$ \\
\hline Liaoning & 45 & $17 / 45$ & $1 / 17$ & $7 / 17$ & $7 / 17$ & $5 / 17$ & $4 / 17$ & $10 / 17$ & $15 / 17$ & $0 / 17$ & $0 / 17$ & $0 / 17$ \\
\hline Northeast in China (total) & 105 & $35 / 105$ & $4 / 35$ & $16 / 35$ & $12 / 35$ & $9 / 35$ & $9 / 35$ & $21 / 35$ & $26 / 35$ & $0 / 35$ & $0 / 35$ & $0 / 35$ \\
\hline
\end{tabular}

the PCV3 genome were amplified and sequenced. The complete genome sequences of the 13 samples infected with PCV3 identified in this study were deposited in GenBank under accession numbers MH277107-MH277119. Their genomes were two sizes: 1999 (MH277118) and 2000 nucleotides in length. The alignment of multiple sequences within these 13 PCV3 samples shared $97.9 \%$ to $100 \%$ and $98.8 \%$ to $99.9 \%$ nucleotide similarities at the ORF2 and complete genome sequences, respectively. The samples also shared $97.5 \%$ to $100 \%$ and $97.6 \%$ to $99.8 \%$ nucleotide similarities with available PCV3 ORF2 and complete genome sequences from the NCBI GenBank, respectively. The method described by $\mathrm{Li}$ et al. for dividing clades of PCV3 was used in this study $[21,22]$. A total of 49 complete genome sequences were available in the NCBI database, which were used together with the 13 complete genome sequences (MH277107-MH277119) in this study to divide PCV3 into different clades. The NJ and ML tree was performed to reconstruct the phylogenies to evaluate the PCV3 complete genome sequences. This analysis revealed that the PCV3 strains were divided into two clades, PCV3a and PCV3b (Fig. 2). The majority of the PCV3 strains identified in this study were of the PCV3a and PCV3b clades. A phylogenetic analysis based on the complete genomes indicated that the 13 PCV3 strains in this study clustered more closely around the PCV3 strains identified in United States, South Korea, Italy and Southwest China (Fig. 2). The results revealed that the PCV3 variants in Northeast China exhibited a uniform distribution of the different PCV3 strains across the world.

\section{PCV3 genome with a G deletion induced a truncated replicase protein}

Surprisingly, from the 13 complete PCV3 genome sequences in our study, the genome sequences of strain PCV3-CN2018LN-4 (MH277118) had a G deletion at position 1072 compared with the total genome sequences of the PCV3 strains available in the NCBI database (Fig. 3a). The $\mathrm{G}$ deletion was found to prematurely terminate Rep protein translation, inducing a truncated Rep protein of 283 aa (Fig. 3b). Thus, the influence of this truncated Rep protein on the pathogenicity of PCV3 requires further study.

\section{Discussion}

Since PCV3 was first identified, PCV3 has been associated with PDNS, CT, reproductive failure, as well as cardiac and multi-systemic inflammation in infected pigs $[7,8]$. However, whether PCV3 is capable of inducing a broad range of pathological effects similar to PCV2 requires further study. In this study, the co-infection of PCV3 with other pathogens was investigated using samples isolated from sick pigs. Moreover, PRRSV, PCV2, PRV, CSFV, SIV, TTSuV1, TTSuV2, PPV2, PPV6, and PPV7 were detected in the PCV3-positive tissue samples. Although no co-infections with CSFV, SIV, or PRV were detected in the PCV3-positive tissue samples, a high prevalence of PCV2, PPV6, and PPV7 existed in the PCV3-positive pigs. Previous studies have identified PCV3 and TTSuV1 co-infections in PDNS sows from the United States [8]. Moreover, a high co-infection rate of TTSuV1 and TTSuV2 with PCV3 was detected among clinically healthy sows [23], whereas a co-infection of PCV3 with PRRSV existed in pigs exhibiting severe respiratory disease [20]. Furthermore, a single PCV3 infection was found in pigs with reproductive failure [15]. In the present study, a single PCV3 infection was observed in four tissue of the tissue samples. In addition, this is the first study to report a high prevalence of PPV6 and PPV7 co-infection in PCV3-positive pigs. However, further study is required to elucidate whether PCV3 alone or co-infection with PCV2, PPV6, or PPV7 is involved in the pathogenicity exhibited in pigs. Therefore, there is an urgent need to isolate various PCV3 strains in vitro and evaluate the pathogenicity in pigs with PCV3 infections or co-infections with the above pathogens. In the present study, we attempted to isolate PCV3 in porcine kidney (PK-15) and swine testis (ST) cells; however, PCV3 was not found in either of the cells after four passages. In addition, an infectious molecular clone was constructed using PK-15 cells to isolate PCV3 but it also failed (data not shown). Thus, it is important to explore new approaches that can be used for successful PCV3 isolation.

PCV3 is widely circulated across the world, especially in China, where it has been detected almost provinces (Fig. 1). Recent epidemiological survey showed the positive rate of PCV3 infection between 19.1 and 39.4\% in some provinces of China [15, 24-26]. In the present 


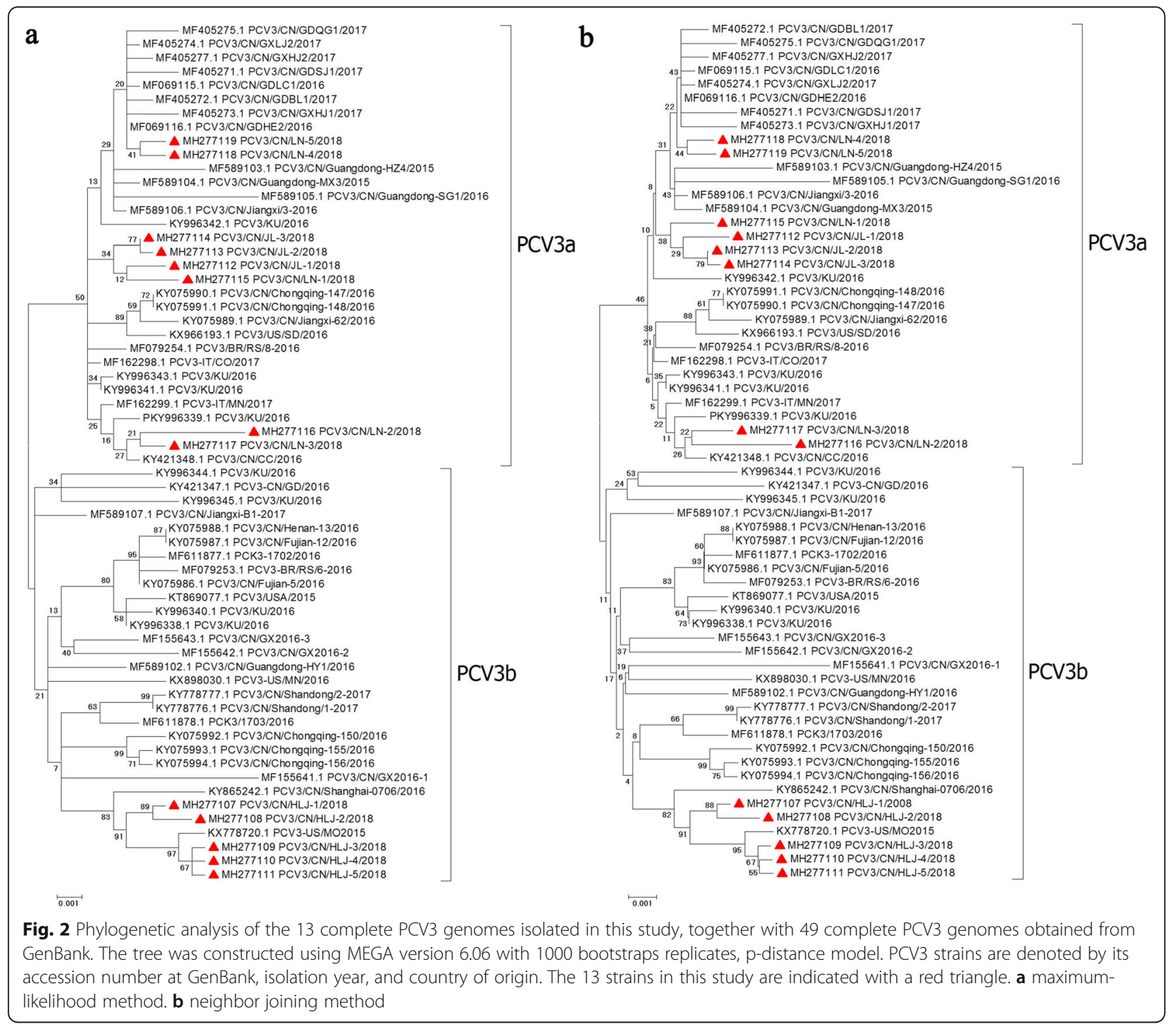

study, the positive rates of PCV3 were $17.8 \%, 66.7 \%$ and $37.8 \%$ in Heilongjiang, Jilin, and Liaoning province, respectively. Limited detection of sample numbers may result in the high prevalence in Jilin and low prevalence in Heilongjiang. However, a greater number of samples are required to verify the positive rate of $\mathrm{PCV} 3$ in Northeast China. The phylogenetic analysis of the PCV3 genome sequences revealed that the PCV3 strains in this study are closely related to strains isolated in United States (KX778720), South Korea (KY996339), Italy (MF162299), and Southwest China (KY421348). These results indicate that the PCV3 variants in Northeast China have a uniform distribution with different PCV3 strains across the world. A possible reason for this might be the presence of PCV3 infections within swine herds over long periods of time. Previous studies have found that PCV3 infections in China can be traced back to
1996 [27]. In addition, a common recent ancestor analysis suggests that PCV3 lineages have been circulating among swine herds over the past 50 years [26, 28].

The PCV2 strains were divided into different genotypes based on an analysis of the ORF2 gene sequences, from which a distance genotype was calibrated [29]. Fu et al. divided PCV3 was divided into three clades based on the aa codons in ORF2 $(24,27,77,104$, and 150 aa) [26]. Fux et al. divided PCV3 into a1, a2, b1, and b2 subtypes based on the aa codons in ORF1 (122 aa), ORF2 (24, 27, 77, and 150 aa), and ORF3 (1, 4, and 27 aa) [30]. Subsequently, Li et al. study showed the phylogenetic analysis of PCV3 did not show clear clusters and consistent in different references based on the sequences of the ORF2 gene. But, by ML, maximum clade credibility (MCC), and NJ methods to reconstruct the phylogenies of PCV3 using complete coding sequences, PCV3 could 


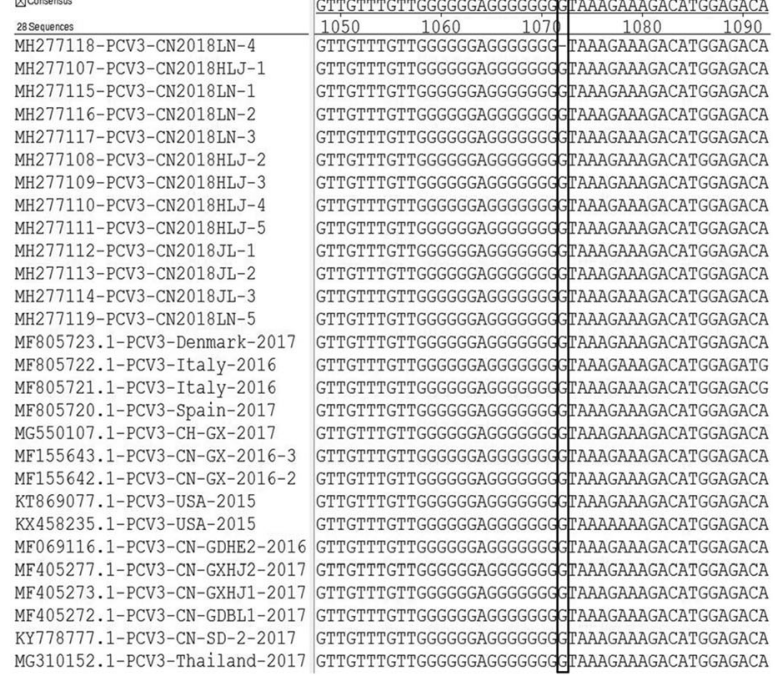

b

\begin{tabular}{|c|c|c|}
\hline & EALFRRFTK & KKDMETV \\
\hline & & \\
\hline H277118-PCV3-CN2018LN-4 & EWYSSENIRGKLEALFRRFTKVVCWG & \\
\hline 1277107-PCV3-CN2018HL & EWYSSENIRGKLEALFRRFTKVVCWGEGG & VKKDMET \\
\hline 1277115-PCV3-CN2018LN & & \\
\hline $1277116-$ & GKLEALFRRFTKVVCWGEGG & VKKDME \\
\hline & & \\
\hline 1277108 & CWGEG & JKKDME \\
\hline & & \\
\hline $1277110-1$ & CWGE & VKKDI \\
\hline & & \\
\hline $112-1$ & CWG & VKKDI \\
\hline & & \\
\hline & EWC & VKKDI \\
\hline & & \\
\hline & EV & JKKD \\
\hline & & \\
\hline & Fir & JKKD \\
\hline & EW & JKKDI \\
\hline & & \\
\hline & & JKKD \\
\hline & & \\
\hline & & \\
\hline & & \\
\hline & EWYSSENIR & JKKDMETVY \\
\hline & & \\
\hline & EWYSSE & VKKDMET \\
\hline & & \\
\hline & & \\
\hline & & \\
\hline
\end{tabular}

Fig. 3 Multiple alignments of the complete PCV3-CN2018LN-4 genome sequences and amino acids of the Rep protein with the other 27 PCV3 strains. (a) Complete PCV3 genome sequences between the sites 1048 and 1092. PCV3-CN2018LN-4 contains a G deletion at position 1072 compared with the other PCV3 strains. The deletion of G is indicated by a block. (b) PCV3 Rep protein between amino acid sites 255 and 296. There is a 13-amino acid deletion of PCV3-CN2018LN-4 from the amino acid positions 284 to 296 . The deletion of 13 amino acids is indicated with a block

be stably divided into two clades, PCV3a and PCV3b, and further confirmed by principle component analysis (PCA) [21, 22]. Li et al. study provided a comprehensive genotype identification. In the present study, we referred to the methods used by $\mathrm{Li}$ et al. to divide the strains of PVC3 into different clades. We used the NJ and ML tree to reconstruct the phylogenies of PCV3 complete genome sequences. Two different trees displayed similar structures in the division of PCV3 into different clades. PCV3 strains could be divided into two clades, PCV3a and PCV3b. Therefore, phylogenetic analysis of complete coding sequences might be considered as PCV3 clade division in the future.

A previously study showed that the $\mathrm{PCV} 3$ genome was 1999-2001 nucleotides in length [8, 25, 30]. Moreover, the genome consisted of two inverse ORFs, coding for the Rep (296 aa) and cap (214 aa) proteins, respectively [8]. In this study, the 13 complete PCV3 genomes were 2000 or 1999 nucleotides in length. However, a G deletion at position 1072 of the PCV3-CN2018LN-4 (MH277118) strain was observed, which differs from previous reports. Interestingly, the $\mathrm{G}$ deletion at position of 1072 was in the coding region of the Rep protein, as the termination codon, TAA, is situated after the G gene. Thus, the $\mathrm{G}$ deletion induced a truncated Rep protein of 283 aa. This finding suggests that two different lengths (296 aa and 283 aa) of the Rep protein exist in PCV3. However, the impact of the truncated Rep protein (283 aa) in PCV3 infections requires further study.

\section{Conclusions}

PCV3 could be divided into two clades using complete coding sequences. A new strain PCV3-CN2018LN-4 (MH277118) had a G deletion in the coding region of the Rep protein and induced a truncated Rep protein of 283 aa, this finding suggests that two different lengths (296 aa and 283 aa) of the Rep protein exist in PCV3. There is a high prevalence of PPV6 and PPV7 co-infection in PCV3-positive pigs.

\section{Methods}

\section{Tissue samples}

In January 2018, a total of 105 lung tissue samples isolated from sick pigs were collected from seven large pig farms in Northeast China, three farms in Heilongjiang, one farm in Jilin, and three farms in Liaoning. All pigs were euthanized by an anesthetic overdose with the pentobarbital $(100 \mathrm{mg} / \mathrm{kg}$ of body weight) before collecting the samples. Each pig farm consisted of a herd of over 10,000 sows. The age of all sampled pigs ranged from 4 to 16 weeks.

\section{PCV3 detection}

Viral DNA was extracted from the tissue samples using a Tissue DNA Kit (OMEGA Bio-Tek, Georgia, USA) according to the manufacturers' instructions and tested for PCV3 using PCR, as described previously [9]. Briefly, the detection of PCV3 by PCR was performed in a $25 \mu \mathrm{L}$ final volume, consisting of $2 \mu \mathrm{L}$ DNA, $1 \mu \mathrm{L}$ of each $10 \mu \mathrm{M}$ primer, $2 \mu \mathrm{L}(2.5 \mathrm{mmol} / \mathrm{L}) \mathrm{dNTPs}, 5 \mu \mathrm{L}$ PCR buffer, $0.5 \mu \mathrm{L}$ DNA 
polymerase (TransGen Biotech, Beijing, China), and $\mathrm{dd}_{2} \mathrm{O}$ up to $25 \mu \mathrm{L}$. The profile of the PCR conditions were as follows: $95{ }^{\circ} \mathrm{C}$ for $2 \mathrm{~min}, 35$ cycles of $95{ }^{\circ} \mathrm{C}$ for $20 \mathrm{~s}, 56{ }^{\circ} \mathrm{C}$ for $20 \mathrm{~s}$ and $72{ }^{\circ} \mathrm{C}$ for $20 \mathrm{~s}$, and a final extension at $72{ }^{\circ} \mathrm{C}$ for $5 \mathrm{~min}$. The amplified products were analyzed on $1 \%$ agarose gels and the positive amplicons were sequenced (Comate Biosciences Co., Jilin, China).

\section{Co-infection detection}

For PCV3-positive tissue samples, viral RNA was extracted using a commercial RNA extraction kit (Sangon Biotech, Shanghai, China) in accordance with the instruction manual. PRRSV, SIV, and CSFV were detected using a one-step reverse transcription PCR Kit (TransGen Biotech, Beijing, China); the primers used for detection were the same as that described previously [31-33]. In addition, the DNA from PCV3-positive tissue samples was selected for the detection of PCV2, TTSuV1, TTSuV2, PPV2, PPV6, PPV7, and PRV, using the same primers as those previously described [34-38].

\section{PCV3 genome sequencing and phylogenetic analysis}

To obtain a full-length sequence of PCV3 for phylogenetic analysis, three pairs of overlapping PCR primers were utilized for whole genome sequencing as previously described [8]. PCR assays were performed using TransGen Biotech DNA polymerase (TransGen Biotech, Beijing, China). The PCR profile conditions were as follows: $95{ }^{\circ} \mathrm{C}$ for $2 \mathrm{~min}, 35$ cycles at $95{ }^{\circ} \mathrm{C}$ for $20 \mathrm{~s}, 50{ }^{\circ} \mathrm{C}$ for $20 \mathrm{~s}$, and $72{ }^{\circ} \mathrm{C}$ for $40 \mathrm{~s}$, with a final extension at $72{ }^{\circ} \mathrm{C}$ for $5 \mathrm{~min}$. The PCR products were purified using a Gel Extraction Kit (Bioer Technology, Hangzhou, China) and cloned into a pEASY-Blunt vector (TransGen Biotech, Beijing, China) for sequencing (Comate Biosciences Co., Jilin, China). A total of 13 complete PCV3 genome sequences were obtained in this study and all of the available complete PCV3 genomes from the NCBI GenBank were used for alignment and phylogenetic analysis. Multiple sequence alignments were performed using Lasergene software with the Clustal W program implemented in DNAStar software. A phylogenetic analysis of the complete PCV3 genome was reconstructed using MEGA 6.06 software with the p-distance-based, maximum-likelihood (ML) method and neighbor joining (NJ) method with 1000 bootstrap replicates.

\section{Abbreviations}

A: Alanine; K: Lysine; ORFs: Open reading frames; PCV3: Porcine circovirus type 3; PPV6: Porcine parvovirus 6; PPV7: Porcine parvovirus 7; R: Arginine; aa: amino acid; rep: Replicase protein; $\vee$ : Valine

\section{Acknowledgements}

We would like to thank the native English speaking scientists of Elixigen Company (Huntington Beach, California) for editing our manuscript.

\section{Funding}

This work was supported by the following Grants: National Key Research and Development Program of China (grant number 2017YFD0500101 and 2016YFD0500401), National Natural Science Foundation of China (grant number 31272573). The funders did not play any role in the design, conclusions or interpretation of the study.

\section{Availability of data and materials}

All relevant data are within this paper. The data analyzed during the current study are available from the corresponding author on reasonable request.

\section{Authors' contributions}

NYJ and HJL designed the experiments. ZH, CZX, SBW and JFL performed the experiments. ZH, KLZ, FLN, HZ analyzed the data and drew the graphs. ZH, YCG and WW wrote the paper. All authors approved the final manuscript.

\section{Ethics approval}

Pigs clinical samples used in this study had obtained a written consent from farm owners and carried out in strict accordance with the Animal Ethics Procedures and Guidelines of the People's Republic of China. All of the animal protocols in this study were approved by the Ethics Committee of Military Veterinary medicine Institute.

\section{Consent for publication}

Not applicable.

\section{Competing interests}

All authors have declared no conflict of interest.

\section{Publisher's Note}

Springer Nature remains neutral with regard to jurisdictional claims in published maps and institutional affiliations.

\section{Author details}

${ }^{1}$ College of Veterinary Medicine, Northeast Agricultural University, Harbin 150030, China. ${ }^{2}$ Institute of Military Veterinary medicine, Academy of Military Medical Sciences, Changchun 130122, China. ${ }^{3}$ College of Animal Science and Technology, Jilin Agricultural University, Changchun 130118, China. ${ }^{4}$ jilin Fengman area Animal Prevention and Control Center, Jilin 132013, China. ${ }^{5}$ College of Veterinary Medicine, Jilin University, Changchun 130012, China. ${ }^{6}$ College of Animal Science and Technology, Guangxi University, Nanning 530004, China. ${ }^{7}$ Jiangsu Co-Innovation Center for the Prevention and Control of Important Animal Infectious Disease and Zoonoses, Yangzhou University, Yangzhou 225009, China.

Received: 28 June 2018 Accepted: 28 September 2018

Published online: 26 October 2018

\section{References}

1. Rosario K, Breitbart M, Harrach B, Segales J, Delwart E, Biagini P, Varsani A. Revisiting the taxonomy of the family Circoviridae: establishment of the genus Cyclovirus and removal of the genus Gyrovirus. Arch Virol. 2017; 162(5):1447-63.

2. Saha D, Lefebvre DJ, Ducatelle R, Doorsselaere JV, Nauwynck HJ. Outcome of experimental porcine circovirus type 1 infections in mid-gestational porcine foetuses. BMC Vet Res. 2011;7:64.

3. Tischer I, Rasch R, Tochtermann G. Characterization of papovavirus-and picornavirus-like particles in permanent pig kidney cell lines. Zentralbl Bakteriol Orig A. 1974;226(2):153-67.

4. Baekbo P, Kristensen CS, Larsen LE. Porcine circovirus diseases: a review of PMWS. Transbound Emerg Dis. 2012;59 Suppl 1:60-7.

5. Karuppannan AK, Ramesh A, Reddy YK, Ramesh S, Mahaprabhu R, Jaisree S, Roy P, Sridhar R, Pazhanivel N, Sakthivelan SM, et al. Emergence of porcine circovirus 2 associated reproductive failure in southern India. Transbound Emerg Dis. 2016;63(3):314-20.

6. Opriessnig T, Meng XJ, Halbur PG. Porcine circovirus type 2 associated disease: update on current terminology, clinical manifestations, pathogenesis, diagnosis, and intervention strategies. J Vet Diagn Invest. 2007;19(6):591-615. 
7. Phan TG, Giannitti F, Rossow S, Marthaler D, Knutson TP, Li L, Deng X, Resende T, Vannucci F, Delwart E. Detection of a novel circovirus PCV3 in pigs with cardiac and multi-systemic inflammation. Virol J. 2016;13(1):184.

8. Palinski R, Pineyro P, Shang P, Yuan F, Guo R, Fang Y, Byers E, Hause BM. A novel porcine circovirus distantly related to known circoviruses is associated with porcine dermatitis and nephropathy syndrome and reproductive failure. J Virol. 2017;91(1)

9. Chen GH, Tang XY, Sun Y, Zhou L, Li D, Bai Y, Mai K, Li YY, Wu QW, Ma JY Development of a SYBR green-based real-time quantitative PCR assay to detect PCV3 in pigs. J Virol Methods. 2018;251:129-32.

10. Kedkovid R, Woonwong Y, Arunorat J, Sirisereewan C, Sangpratum N, Lumyai M, Kesdangsakonwut S, Teankum K, Jittimanee S,

Thanawongnuwech R. Porcine circovirus type 3 (PCV3) infection in grower pigs from a Thai farm suffering from porcine respiratory disease complex (PRDC). Vet Microbiol. 2018;215:71-6.

11. Li L, McGraw S, Zhu K, Leutenegger CM, Marks SL, Kubiski S, Gaffney P, Dela Cruz FN, Jr., Wang C, Delwart E et al: Circovirus in tissues of dogs with vasculitis and hemorrhage. Emerg Infect Dis 2013, 19(4):534-541.

12. Bexton S, Wiersma LC, Getu S, van Run PR, Verjans GM, Schipper D, Schapendonk CM, Bodewes R, Oldroyd L, Haagmans BL, et al. Detection of circovirus in foxes with meningoencephalitis, United Kingdom, 2009-2013. Emerg Infect Dis. 2015;21(7):1205-8.

13. Hong YT, Kang M, Jang HK. Pathogenesis of duck circovirus genotype 1 in experimentally infected Pekin ducks. Poult Sci. 2018.

14. Chen GH, Mai KJ, Zhou L, Wu RT, Tang XY, Wu JL, He LL, Lan T, Xie QM, Sun $Y$, et al. Detection and genome sequencing of porcine circovirus 3 in neonatal pigs with congenital tremors in South China. Transbound Emerg Dis. 2017;64(6):1650-4.

15. Ku X, Chen F, Li P, Wang Y, Yu X, Fan S, Qian P, Wu M, He Q. Identification and genetic characterization of porcine circovirus type 3 in China. Transbound Emerg Dis. 2017;64(3):703-8.

16. Kwon T, Yoo SJ, Park CK, Lyoo YS. Prevalence of novel porcine circovirus 3 in Korean pig populations. Vet Microbiol. 2017;207:178-80.

17. Franzo G, Legnardi M, Hjulsager CK, Klaumann F, Larsen LE, Segales J, Drigo M. Full-genome sequencing of porcine circovirus 3 field strains from Denmark, Italy and Spain demonstrates a high within-Europe genetic heterogeneity. Transbound Emerg Dis. 2018;65(3):602-6.

18. Tochetto C, Lima DA, Varela APM, Loiko MR, Paim WP, Scheffer CM, Herpich $\mathrm{Jl}$, Cerva C, Schmitd C, Cibulski SP, et al. Full-genome sequence of porcine circovirus type 3 recovered from serum of sows with stillbirths in Brazil. Transbound Emerg Dis. 2018;65(1):5-9.

19. Shen H, Liu X, Zhang P, Wang L, Liu Y, Zhang L, Liang P, Song C. Genome characterization of a porcine circovirus type 3 in South China. Transbound Emerg Dis. 2018;65(1):264-6.

20. Zhai SL, Zhou X, Zhang H, Hause BM, Lin T, Liu R, Chen QL, Wei WK, Lv DH, Wen $\mathrm{XH}$, et al. Comparative epidemiology of porcine circovirus type 3 in pigs with different clinical presentations. Virol J. 2017;14(1):222.

21. Li G, He W, Zhu H, Bi Y, Wang R, Xing G, Zhang C, Zhou J, Yuen K, Gao G, et al. Origin, genetic diversity, and evolutionary dynamics of novel porcine circovirus 3. Advanced science. 2018. https://doi.org/10. 1002/advs.201800275

22. Li G, Wang H, Wang S, Xing G, Zhang C, Zhang W, Liu J, Zhang J, Su S, Zhou J. Insights into the genetic and host adaptability of emerging porcine circovirus 3. Virulence. 2018. https://doi.org/10.1080/21505594.2018.1492863.

23. Zheng S, Shi J, Wu X, Peng Z, Xin C, Zhang L, Liu Y, Gao M, Xu S, Han H, et al. Presence of torque Teno sus virus 1 and 2 in porcine circovirus 3-positive pigs. Transbound Emerg Dis. 2018;65(2):327-30.

24. Zou Y, Zhang N, Zhang J, Zhang S, Jiang Y, Wang D, Tan Q, Yang Y, Wang N. Molecular detection and sequence analysis of porcine circovirus type 3 in sow sera from farms with prolonged histories of reproductive problems in Hunan, China. Arch Virol. 2018. https://doi.org/10.1007/s00705-018-3914-7.

25. Wen S, Sun W, Li Z, Zhuang X, Zhao G, Xie C, Zheng M, Jing J, Xiao P, Wang $M$, et al. The detection of porcine circovirus 3 in Guangxi, China. Transbound Emerg Dis. 2018:65(1):27-31.

26. Fu X, Fang B, Ma J, Liu Y, Bu D, Zhou P, Wang H, Jia K, Zhang G. Insights into the epidemic characteristics and evolutionary history of the novel porcine circovirus type 3 in southern China. Transbound Emerg Dis. 2018; 65(2):e296-303.

27. Sun J, Wei L, Lu Z, Mi S, Bao F, Guo H, Tu C, Zhu Y, Gong W. Retrospective study of porcine circovirus 3 infection in China. Transbound Emerg Dis. 2018;65(3):607-13.
28. Saraiva GL, Vidigal PMP, Fietto JLR, Bressan GC, Silva Junior A, de Almeida MR. Evolutionary analysis of porcine circovirus 3 (PCV3) indicates an ancient origin for its current strains and a worldwide dispersion. Virus Genes. 2018.

29. Segales J, Olvera A, Grau-Roma L, Charreyre C, Nauwynck H, Larsen L, Dupont K, McCullough K, Ellis J, Krakowka S, et al. PCV-2 genotype definition and nomenclature. The Veterinary record. 2008;162(26):867-8.

30. Fux R, Sockler C, Link EK, Renken C, Krejci R, Sutter G, Ritzmann M, Eddicks $M$. Full genome characterization of porcine circovirus type 3 isolates reveals the existence of two distinct groups of virus strains. Virol J. 2018;15(1):25.

31. Nilubol D, Tripipat T, Hoonsuwan T, Tipsombatboon P, Piriyapongsa J. Genetic diversity of the ORF5 gene of porcine reproductive and respiratory syndrome virus (PRRSV) genotypes I and II in Thailand. Arch Virol. 2013; 158(5):943-53.

32. Paton DJ, McGoldrick A, Greiser-Wilke I, Parchariyanon S, Song JY, Liou PP, Stadejek T, Lowings JP, Bjorklund H, Belak S. Genetic typing of classical swine fever virus. Vet Microbiol. 2000;73(2-3):137-57.

33. Richt JA, Lager KM, Clouser DF, Spackman E, Suarez DL, Yoon KJ. Real-time reverse transcription-polymerase chain reaction assays for the detection and differentiation of north American swine influenza viruses. J Vet Diagn Invest. 2004;16(5):367-73.

34. Xiao CT, Gerber PF, Gimenez-Lirola LG, Halbur PG, Opriessnig T. Characterization of porcine parvovirus type 2 (PPV2) which is highly prevalent in the USA. Vet Microbiol. 2013;161(3-4):325-30.

35. Schirtzinger EE, Suddith AW, Hause BM, Hesse RA. First identification of porcine parvovirus 6 in North America by viral metagenomic sequencing of serum from pigs infected with porcine reproductive and respiratory syndrome virus. Virol J. 2015;12:170.

36. Xing $X$, Zhou $H$, Tong $L$, Chen $Y$, Sun $Y$, Wang $H$, Zhang G. First identification of porcine parvovirus 7 in China. Arch Virol. 2018;163(1):209-13.

37. Pogranichnyy RM, Yoon KJ, Harms PA, Swenson SL, Zimmerman JJ, Sorden SD. Characterization of immune response of young pigs to porcine circovirus type 2 infection. Viral Immunol. 2000;13(2):143-53.

38. Kekarainen T, Lopez-Soria S, Segales J. Detection of swine torque Teno virus genogroups 1 and 2 in boar sera and semen. Theriogenology. 2007;68(7): $966-71$.

Ready to submit your research? Choose BMC and benefit from

- fast, convenient online submission

- thorough peer review by experienced researchers in your field

- rapid publication on acceptance

- support for research data, including large and complex data types

- gold Open Access which fosters wider collaboration and increased citations

- maximum visibility for your research: over $100 \mathrm{M}$ website views per year

At $\mathrm{BMC}$, research is always in progress.

Learn more biomedcentral.com/submissions 